\title{
Ética na Educação Básica nas Séries Iniciais: análise de um material educativo paradidático
}

\author{
Ethics in Basic Education in the Early Grades: analysis of a paradidatic educational material \\ La ética en la Educación Básica en los Primeros Grados: análisis de un material educativo \\ paradidático
}

Recebido: 29/09/2021 | Revisado: 04/10/2021 | Aceito: 11/10/2021 | Publicado: 12/10/2021

\author{
Astrid Pantoja das Neves Matos \\ ORCID: https://orcid.org/0000-0003-1343-3924 \\ Universidade Estadual de Mato Grosso do Sul, Brasil \\ E-mail: astriddasneves@ hotmail.com \\ Antonio Sales \\ ORCID: https://orcid.org/0000-0001-5515-6625 \\ Universidade Estadual de Mato Grosso do Sul, Brasil \\ E-mail: profsales2@gmail.com
}

\begin{abstract}
Resumo
Neste artigo, apresentamos uma pesquisa qualitativa documental intitulada. "Ética na educação básica nas séries iniciais com análise de um material educativo paradidático". A Ética na educação envolve certas dificuldades na atuação do docente comprometido com a aprendizagem dos alunos, sendo sua definição um conjunto de princípios que orientam as relações humanas e norteiam as decisões vencendo os dilemas encontrados no ambiente sócio-moral. Dessa forma a criança adquire experiência nas relações interpessoais na escola desenvolvendo a moralidade, o que nos permite discutir a importância do papel da ética nas escolas que vem auxiliar na construção de valores de uma sociedade. Nesse contexto, a análise dos documentos seguiu os conteúdos de quatro categorias; procedimental, conceitual, atitudinal, factual que facilita no processo de ensino-aprendizagem em sua execução. Nesta perspectiva, esse texto vem ajudar na formação continuada do professor da educação básica, com reflexões sobre a atuação do docente em sala de aula.
\end{abstract}

Palavras-chave: Prática docente; Dilemas éticos; Formação docente.

\begin{abstract}
In this article, we present a qualitative documentary research entitled. "Ethics in basic education in the early grades with analysis of a paradidactic educational material". Ethics in education involves certain difficulties in the performance of the teacher committed to student learning, and its definition is a set of principles that guide human relationships and guide decisions, overcoming the dilemmas found in the socio-moral environment. In this way, the child acquires experience in interpersonal relationships at school, developing morality, which allows us to discuss the importance of the role of ethics in schools, which helps in the construction of values in a society. In this context, the analysis of documents followed the contents of four categories; procedural, conceptual, attitudinal, factual that facilitates the teaching-learning process in its execution. In this perspective, this text helps in the continuing education of basic education teachers, with reflections on the role of teachers in the classroom.
\end{abstract}

Keywords: Teaching practice; Ethical dilemmas; Teacher training.

\section{Resumen}

En este artículo presentamos una investigación documental cualitativa titulada. "Ética en la educación básica en los primeros grados con análisis de un material educativo paradidáctico". La ética en la educación implica ciertas dificultades en el desempeño del docente comprometido con el aprendizaje del alumno, y su definición es un conjunto de principios que orientan las relaciones humanas y orientan las decisiones, superando los dilemas encontrados en el entorno socio-moral. De esta manera, el niño adquiere experiencia en las relaciones interpersonales en la escuela, desarrollando la moralidad, lo que nos permite discutir la importancia del papel de la ética en la escuela, lo que ayuda 
en la construcción de valores en una sociedad. En este contexto, el análisis de documentos siguió el contenido de cuatro categorías; procedimental, conceptual, actitudinal, factual que facilita el proceso de enseñanza-aprendizaje en su ejecución. En esta perspectiva, este texto ayuda en la formación continua de los docentes de educación básica, con reflexiones sobre el papel del docente en el aula.

Palabras clave: Práctica docente; Dilemas éticos; Formación de profesores.

\section{Introdução}

O presente artigo "Ética na educação básica nas séries iniciais" é uma pesquisa qualitativa com análise de um material paradidático. Envolve o papel do docente como mediador comprometido socialmente com seus alunos e preocupado com a aprendizagem.

Dessa forma, a ética pode ser interpretada tanto quanto na moral, ou como conceitos que tomam como base a preocupação com o bem-estar humano, almejando não cometer atos que prejudiquem, de forma definitiva e deliberada, outras pessoas (Thakur \& Lahiry, 2019).

A análise do documento seguiu tipologia do conteúdo proposta por Zabala (1998). Este autor considera que os conteúdos de ensino podem ser classificados em quatro categorias que são: procedimental, conceitual, atitudinal, factual e são definidos como conteúdo que são apreendidos no momento em que são praticados. Dessa forma são agrupados em fatos, procedimentos, valores, atitudes e normas.

A ética é a ciência do comportamento moral dos homens em sociedade, ou seja, é a ciência de uma forma específica de comportamento humano "enquanto conhecimento científico, a ética deve aspirar a racionalidade e a objetividade mais completas e, ao mesmo tempo, deve proporcionar conhecimentos sistemáticos, metódicos e, no limite do possível, comprováveis". (Vasquez, 2003).

Dessa forma segundo Piaget (1973), a criança deve fabricar conhecimento por meio do trabalho coletivo, fazendo uma junção do aprendizado prévio familiar com a experiência do ambiente sócio-moral na escola.

\section{Fundamentação Teórica}

Segundo Vries e Zan (1998), a ética é um conjunto de princípios e valores que envolve decisões com o fim de orientar as relações humanas. Esses valores têm de ser válidos para todas as pessoas por um tempo indefinido. A ética é aliada da sociedade, o desafio do indivíduo é andar guiado por esses princípios, seguindo as regras imposta pela sociedade, e ao mesmo tempo vencendo os dilemas encontrados no decorrer desse caminho.

Vries e Zan, (1998), apoiam-se na teoria de Piaget segundo o qual a criança passa por quatro estágios para adquirir e construir o conhecimento, propondo a criação de um ambiente sócio-moral na instituição de ensino. Piaget (1973), defende que a criança deve construir sua autonomia por meio do trabalho coletivo. Para o autor "o ambiente sócio-moral é toda a rede de relações interpessoais que forma a experiência da criança na escola". Piaget segundo Vries e Zan (1998), descreve significativamente como se desenvolve a moralidade na criança, onde relata que existem dois tipos de moral: a heterônima, que se baseia na obediência, na submissão e no castigo; e a autônoma que está fundamentada no respeito mútuo e na reciprocidade.

Nesse ambiente sócio-moral, cooperativo que envolve muitas trocas, sendo uma rotina especifica detalhada para cada faixa etária, com roda, calendário, hora do lanche, hora da atividade, hora da contação de história e a hora da organização do espaço. Dessa forma ensinando as crianças a se relacionar no ambiente sem colocar o colega em risco, brincar ou bater pedir desculpas, resolvendo seus próprios problemas, construindo sua autonomia.

A escola influencia o desenvolvimento social e moral quer pretenda fazer isso ou não. Os professores comunicam continuamente mensagens sociais e morais (...) a escola ou a creche não são e não podem ser livres de valores ou 
neutros quanto a esses. Por bem ou por mal, os professores estão engajados na educação social e moral (...). Quando os professores dizem às crianças que estas devem e o que não devem fazer, o que as crianças escutam é o que é bom ou mau, certo ou errado (De Vries \&Zan 1998, p. 35).

Seguindo o pensamento das autoras citadas acima, a influência das escolas está inserida no desenvolvimento moral e social da criança, uma oportunidade para entendermos como é importante discutir o papel da ética nas escolas. Após esse entendimento, o estudo da ética nas escolas auxilia na construção de valores que fortalecem uma sociedade. Todos os processos que ocasionam mudanças nas concepções infantis devem ser ligados aos conflitos geradores pela interação sujeito e objeto (Nunes, 1990).

As Diretrizes Curriculares para a Educação Infantil (DCMsEI) falam sobre três princípios: éticos, estéticos e políticos. Sobre os princípios éticos comenta-se: "Princípios éticos: valorização da autonomia, da responsabilidade e do respeito ao bem comum, ao meio ambiente e às diferentes culturas, identidades e singularidades" (Brasil, 2009).

Pensando em princípios, "a reflexividade acerca da docência pode assumir uma via de mão dupla, pois, ao passo que possui potencial para apresentar a dificuldade ou problema, permite, ao mesmo tempo, elaborar propostas de resolução e testálas in loco" (Bagnara \& Adams, 2020, p.8).

Segundo Delors (2000), a postura firme e responsável dos professores contribui no processo de aprendizagem. Empiricamente o professor torna-se modelo para seus educandos. Sendo um ser que vive em sociedade, cabe a ele com competência ajudar seu educando a se integrar na sociedade de forma ativa e participativa.

O professor deve estabelecer uma nova relação com quem está aprendendo: passar do papel de solista ao de acompanhante, tornando-se não mais alguém que transmite conhecimento, mas aquele que ajuda seus alunos a encontrar, organizar e gerir o saber, guiando, mas não modelando os espíritos, demonstrando grande firmeza quanto aos valores fundamentais que devem orientar toda a vida (Delors, 2000, p. 63).

De acordo com essa perspectiva, o professor é, em muitas situações, a única referência que o aluno tem para se espelhar, seguindo esse pressuposto o docente deve apresentar a capacidade de guiar seus discentes.

Gostaria, por outro lado, de sublinhar a nós mesmos, professores e professoras, a nossa responsabilidade ética no exercício de nossa tarefa docente. (...) Não é possível pensar os seres humanos longe, sequer, da ética, quanto mais fora dela. Estar longe ou pior, fora da ética, entre nós, mulheres e homens, é uma transgressão. É por isso que transformar a experiência educativa em puro treinamento técnico é amesquinhar o que há de fundamentalmente humano no exercício educativo: o seu carácter formador. Se se respeita a natureza do ser humano, o ensino dos conteúdos não pode dar-se alheio à formação moral do educando. Educar é substantivamente formar (Freire, 1996, p. 17-19).

Nos Parâmetros Curriculares Nacionais (PCN), "A ética é um eterno pensar, refletir e construir" (Brasil,1997). Os PCN ainda, numa perspectiva transversal, no seu volume 8, titulado como "Ética", traz uma reflexão muito pertinente que legitima a ética no ambiente social, mais precisamente no ambiente escolar, salientando que um indivíduo não pode ser ético por coerção ou por medo de leis que ceife a sua liberdade, mas deverão aprender a ser éticos por entender que esta é a conduta devida a se conviver em sociedade e legitime isso através de ações intrínsecas ao seu ser. Outrossim, nos PCN constam que ao lado do trabalho de ensino, o convívio dentro da escola deve ser organizado de maneira que os conceitos de justiça, respeito e solidariedade sejam vivificados e compreendidos pelos alunos como aliados à perspectiva de uma "vida boa". Dessa forma, os alunos perceberão que esses valores e regras são coerentes com seus projetos de felicidade, assim serão integrados às suas personalidades. 
No campo dos princípios morais que orientam os homens em suas ações perante uma sociedade, existe um conjunto de valores que especificam o bem, o mal e o que é certo ou errado. Sendo um produto histórico social, a ética ilumina a consciência humana à medida que "[...] sustenta e dirige as ações do homem, norteando a conduta individual e social [...] e define o que é a virtude, o bem ou o mal, o certo ou o errado, permitindo ou proibindo, para cada cultura e sociedade" (Souza, 1995).

Procurando compreender e analisar o aspecto da aprendizagem entendendo a relação entre conceito e princípio, buscando motivar a construção do conhecimento proporcionando descobertas de novas estratégias de ensino partindo do conhecimento prévio do aluno.

\section{Metodologia}

É uma pesquisa documental, que examina os fatos existentes na descrição do material paradidático, a análise documental favorece a observação do processo de maturação ou de evolução de indivíduos, grupos, conceitos, conhecimentos, comportamentos, mentalidades, práticas, entre outros (Cellard, 2008).

O que é um documento? Para Cellard (2008) não é tarefa fácil conceituá-lo: "definir o documento representa em si um desafio". Recuperar a palavra "documento" é uma maneira de analisar o conceito e então pensarmos numa definição: "documento: 1. declaração escrita, oficialmente reconhecida, que serve de prova de um acontecimento, fato ou estado; 2. Qualquer objeto que comprove, elucide, prove ou registre um fato, acontecimento; 3. arquivo de dados gerado por processadores de texto" (Hauaiss, 2008). Phillips (1974) expõe sua visão ao considerar que documentos são "quaisquer materiais escritos que possam ser usados como fonte de informação sobre o comportamento humano".

Diferenciá-los segundo sua tipologia conceitual, procedimental ou atitudinal é uma construção intelectual, por vezes sutil e confusa, mas que permite compreender o que ocorre de maneira integrada no processo de ensino-aprendizagem. Pode servir de instrumento descritivo do modelo educacional que lhe é subjacente, além de permitir identificar as incoerências da prática educativa e apontar um caminho para a sua melhoria (Zabala, 1998).

No que pertence aos conteúdos de aprendizagem, é importante destacar que seu significado vai além do ato de ensinar, antes, perpassa pelo sentido dos questionamentos, sobre 'qual o propósito de se ensinar'. Assim, o processo de aprendizagem envolve objetivos educacionais. Neste ponto, os conteúdos devem desenvolver as diversas dimensões, podendo ser distinguidos de acordo com as suas características, em fatos, conceitos, procedimentos, visando o desenvolvimento de uma atitude (Darido et al., 2002).

\subsection{Tipos de Conteúdos}

Com base nos estudos de Zabala (1998), onde ele identifica a importância dos quatros conteúdos procedimental, conceitual, atitudinal, factual nesta proposta de análise de um material educativo paradidático.

\subsubsection{Conteúdos conceituais}

Os conteúdos conceituais na aprendizagem possibilitam o uso de material paradidático que aborda como trabalhar o respeito. De acordo com a teoria de conteúdos conceituais de Zabala (1998) a elaboração de conceitos está vinculada à associação de valores somados á reflexão e tomada de decisões. O termo aprendizagem dos conteúdos conceituais engloba uma série de conceitos que são agrupadas em normas, valores, padrões e regras de comportamento que induzem o grupo a realizar determinado comportamento. Zabala (2008), afirma que, o conteúdo foi descrito como um conceito de algo que devemos aprender e tudo que permite o desenvolvimento das capacidades motoras, afetivas, de relacionamento e de inserção social. 


\subsubsection{Conteúdos procedimentais}

O conteúdo procedimental é definido como um concomitante de ações sistemáticas e dirigidas para a realização de um objetivo. Incluem técnicas, regras, procedimento, métodos dentre outros. Essa aprendizagem é o conjunto de ações ordenadas e com um fim, dirigidas para a realização de um objetivo, mostrando o que o indivíduo deve saber fazer, ou seja, são apreendidos, principalmente, mediante a realização continua das ações que compõem o procedimento em situações sobre o assunto em estudo (Zabala, 2008). Que inclui entre outras coisas habilidades ou estratégias. São conteúdos procedimentais: "ler, desenhar, observar, calcular, classificar, traduzir, recortar, saltar, inferir, espertar, etc.". Conteúdos que, como podemos ver, apesar de terem como denominador comum o fato de serem ações ou conjunto de ações, são suficientemente diferentes para que a aprendizagem de cada um deles tenha características bem específicas (Zabala, 2008).

Não se trata de aprender ações pela descrição e sim pela realização destas. As estratégias de aprendizagem dos conteúdos consistem na execução compreensiva e nas repetições contextualizadas e significativas e não mecânicas (Ramos, 2013).

\subsubsection{Conteúdos atitudinais}

Segundo Zabala (2008), os conteúdos atitudinais, por sua vez, englobam conteúdos relacionados aos valores (solidariedade, responsabilidade, liberdade), atitudes (ajudar os colegas, respeitar o meio ambiente, participar das tarefas escolares) e normas (padrões de comportamento aceitos por um determinado grupo). A aprendizagem dos conteúdos atitudinais segundo o autor, compreendem uma série de conteúdos que podem ser agrupados em valores, atitudes e normas. A aquisição exige atividades mais complexas que os demais, sendo que a compreensão da ideia intrínseca em um valor, norma ou comportamento, por exemplo, não é o suficiente para que a mesma seja apreendida pelo aluno. Assim, a aprendizagem desse tipo de conteúdos são necessários os conhecimentos prévios dos alunos, e suas vivências pessoais.

\subsubsection{Conteúdos factuais}

Os conteúdos factuais se referem aos conhecimentos gerados a partir de fatos, acontecimentos, eventos, dados e fenômenos concretos, que são reproduzidos fielmente, podendo ser evidenciados através de seu caráter solidificado e descritivo. A aprendizagem desse tipo de conteúdo se dá por meio de sua reprodução de forma literal, ou seja, não sendo necessária então a sua compreensão (Zabala, 2008). No fato de cumprimentar uma pessoa mais velha demonstra um ato de respeito.

Ramos (2013), seguindo a perspectiva de Antoni Zabala, aponta que os conteúdos factuais correspondem por muitas vezes caráter arbitrário, portanto não necessitam de uma compreensão, aprende-se pela cópia e memorização. Porém, se relacionados a outros conteúdos, suas estratégias de aprendizagem deixam de ser simplesmente mecânicas.

\section{Resultados e Discussão}

Dentro dessa perspectiva o material paradidático de estudo analisado foi o volume dois da coleção "O que cabe no meu mundo". Que trata do respeito. Escrito por Trindade (2011), Revisora Pedagógica Luciana Avelino Ramos, Ilustração Aadarsh, Editora CEDICC com orientações importantes dadas pelo psicólogo clínico Cláudio Paixão Anastásio de Paula. Com indicações importantes de como ajudar seu filho a aprender sobre valores e virtudes com histórias educativas com objetivo de direcionar suas atitudes e comportamento.

\subsection{Discussão 1}

A discursão 1, irá tratar do trecho de livro mostrado na Figura 1, o qual relata a importância de se respeitar o meio ambiente. O Quadro 1 que segue, mostra as características do conteúdo. 
Figura 1: Relata a importância de respeitar o meio ambiente.

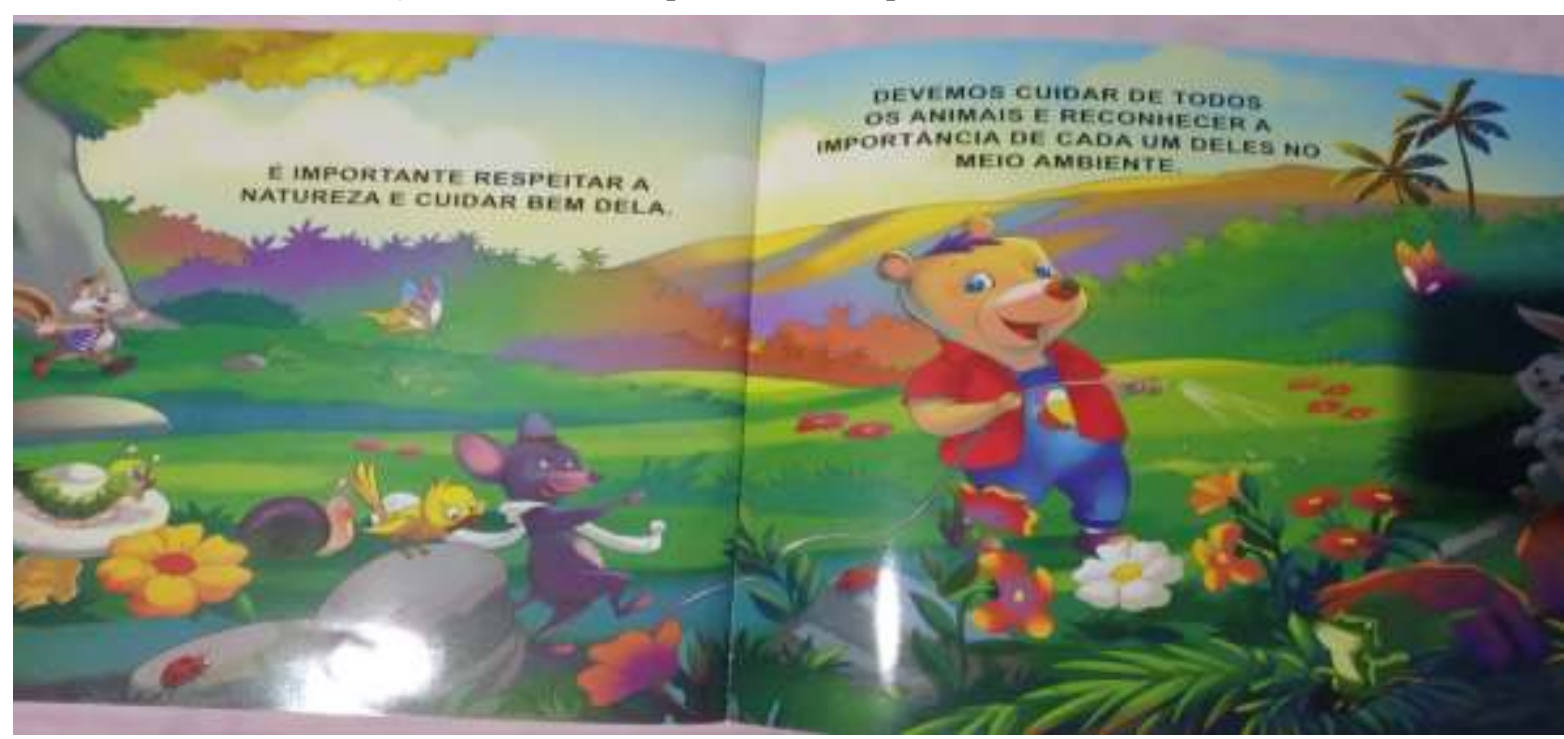

Fonte: Trindade (2011). Disponível em: http: //www.cedicbrasil.com .br,

Quadro 1. Característica do conteúdo.

\begin{tabular}{|c|c|c|}
\hline & Enunciado & CLASSIFICAÇÃO \\
\hline 1 & É importante respeitar a natureza e cuidar dela. & $\begin{array}{c}\text { Atitudinal, conceitual e } \\
\text { factual. }\end{array}$ \\
\hline 2 & $\begin{array}{c}\text { Devemos cuidar de todos os animais e reconhecer a importância de cada um deles no meio } \\
\text { ambiente. }\end{array}$ & $\begin{array}{c}\text { Atitudinal, conceitual e } \\
\text { factual. }\end{array}$ \\
\hline
\end{tabular}

Fonte: Autores.

Respeitar a natureza é uma atitude a ser desenvolvida no estudante. Por outro lado, respeito é um conceito. É uma ideia para cuja apreensão, ou construção, são necessários fatos tais como: exemplos, dados científicos e sociais, bem com procedimentos como ilustrar.

O autor recorreu ao uso de ilustrações e enunciados curtos como procedimentos didáticos, para ensinar o conceito de respeito e destacar o seu valor, isto é, induzir uma atitude ética. Ele enuncia fatos como: "é importante respeitar", devemos "cuidar". "Para cuidar é preciso antes de tudo estar comprometido com o outro, com sua singularidade, ser solidário com suas necessidades, confiando em suas capacidades. Disso depende a construção de um vínculo afetivo entre quem cuida e é cuidado". (Brasil, 1988) Por sua vez, esses enunciados contêm importantes conceitos como "cuidar de...", a relação animalambiente, "respeitar a natureza". As questões que estão implícitas são: o que é cuidar de animais e natureza? Qual a relação entre animal e ambiente? Porque é importante preservar essa relação? No entanto, o texto falha em apontar procedimentos de cuidado. Respeitar, por sua vez, é um procedimento atitudinal. Portanto, o cuidar da criança com educação acrescenta-se a permanência em definir a prioridade e o enfoque que devem ser dados às dimensões desenvolvimento-aprendizagem e ensino, à forma como estas dimensões articulam-se com uma concepção de conhecimento e ação de conhecer, determinantes na formulação de uma abordagem educativa que se concretize em projetos educacionais-pedagógicos (Oliveira, 2010).

\subsection{Discussão 2}

A discursão 2, irá tratar do trecho de livro mostrado na Figura 2, o qual demonstra o respeito pelos pais e mais velhos. O Quadro 2 que segue, mostra as características do conteúdo. 
Figura 2: Demonstrar respeito pelos pais e mais velhos.

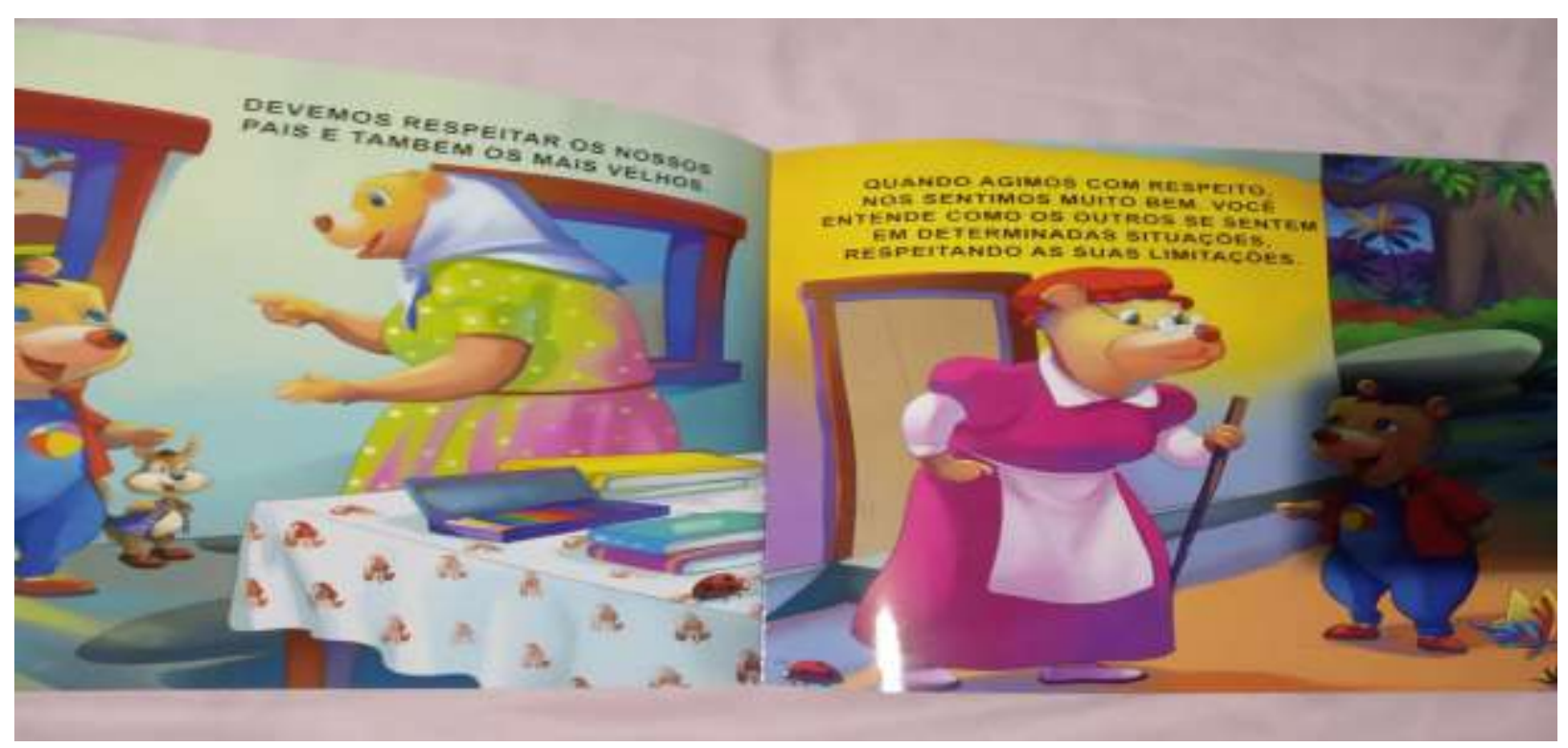

Fonte: Trindade (2011). Disponível em: http: //www.cedicbrasil.com.br

Quadro 2: Característica do conteúdo.

\begin{tabular}{|c|c|c|}
\hline & Enunciado & CLASSIFICAÇ̃̃O \\
\hline 1 & Devemos respeitar os nossos pais e também os mais velhos & $\begin{array}{c}\text { Atitudinal, conceitual, factual e } \\
\text { procedimental }\end{array}$ \\
\hline 2 & $\begin{array}{c}\text { Quando agimos com respeito, nos sentimos muito bem. Você entende como os outros se } \\
\text { sentem em determinadas situações, respeitando as suas limitações. }\end{array}$ & Atitudinal, conceitual e factual \\
\hline
\end{tabular}

Fonte: Autores.

Na Figura 2, pelo o que já visto na figura anterior, sobre o desenvolvimento do valor do respeito, o autor também utilizou procedimentos didáticos, com o objetivo de facilitar a compreensão do conceito de respeitar os pais e os mais velhos. Segundo Piaget (1973), “o respeito constitui o sentimento fundamental que possibilita a aquisição de noções morais”. É preciso, consta no texto, entendermos o que os outros sentem. A preocupação de entender como os outros se sentem, auxilia no processo de desenvolvimento da empatia. Por que devemos respeitar nossos pais e os mais velhos? Respeitar as limitações dos outros faz, nos sentimos bem. O educador Paulo Freire diz que "O respeito à autonomia e à dignidade de cada um é um imperativo ético e não um favor que podemos ou não conceder uns aos outros" (Freire, 1996).

\section{Considerações Finais}

Considerando a ética um conjunto de princípios e valores, que envolve a educação e evolução de uma sociedade. Podemos afirmar que para dar certo o pensamento de Piaget, cabe a escola planejar um ambiente escolar que possa desenvolver a aprendizagem e autonomia. A educação infantil tem o papel de construir o conhecimento da criança para o bem comum.

Entretanto, a responsabilidade do docente e muito importante para formação moral da criança, como um espelho cheio de exemplos positivos ou negativos, um complemento do conhecimento prévio que a crianças traz do ambiente familiar.

Portanto, os conteúdos conceituais, procedimentais, atitudinais e factuais são veículos que sevem de suporte a educação. Que são as seguintes vertentes: aprender a conhecer, aprender a fazer, aprender a viver juntos e aprender a ser. 
Assim, a sociedade tem a ética como uma companheira marcando os passos certos ou errados dos indivíduos, iniciando em casa os primeiros princípios depois no ambiente escolar.

Dessa forma, sugiro uma pesquisa sobre a importância da educação infantil na vida da criança, que passa por todas fases necessárias para um bom desenvolvimento infantil, buscando alcançar uma alfabetização plena e edificante.

\section{Referências}

Bagnara, I. C., \& Adams, A. (2020). Formação inicial de professores conectados com as demandas da docência na contemporaneidade: tematizando o contexto de uma instituição particular. Research, Society and Development, 9(10).

Brasil. (2009). Ministério da Educação e da Cultura. Secretaria da Educação Básica. Resolução $n$ º , de 17 de dezembro de 2009. Fixa as Diretrizes Curriculares para a Educação Infantil. Diário Oficial da União, Brasília.

Brasil. (1997). Secretaria de Educação Fundamental. Parâmetros Curriculares Nacionais. Brasília. <http://portal.mec.gov.br/seb/arquivos/pdf/livro01.pdf>. Acesso em: 18 ago. 2021.

De Vries, R. \& Zan, B. (1998). A ética na educação infantil: o ambiente sóciomoral na escola. Artes Médicas.

Cellard, A. (2008). A análise documental. In: Poupart, J. et al. A pesquisa qualitativa:enfoques epistemológicos e metodológicos. Petrópolis, Vozes.

Darido, S. C. et al. (2002). Resenha do livro A prática educativa, de Antoni Zabala. Revista Brasileira de Ciências do Esporte, 23, (2).

Delors, J. (org.). (2000). Educação: um tesouro a descobrir. UNESCO MEC, 4 ed.

Freire, P. (1996). Pedagogia da Autonomia. (36a ed.), Paz e Terra.

Hauaiss, A. (2008). Minidicionário Hauaiss. (3a ed.) Objetiva.

Nunes, T. (1990). Construtivismo e alfabetização: um balanço crítico. Educação em Revista, 12, 21-23.

Oliveira, Z. de M. (2010). Educação Infantil: muitos olhares, (9a ed.) Cortez.

Piaget, J. (1973). Estudos Sociológicos. Ed. Forense.

Phillipis, B.S. (1974). Pesquisa social: estratégias e táticas. Livraria Agir Editora.

Ramos, K. D. (2013). Aprendizagem colaborativa e a educação problematizadora para um enfoque globalizador. Cadernos da Pedagogia. Ano 6, 6, (12), 105115 .

Souza, S. M. R. de. (1995). Um outro olhar: filosofia. FTD.

Thakur, S, \& Lahiry, S. (2019). Research ethics in the modern era. Indian journal of dermatology, venereology and leprology, 85(4), 351-354.

Trindade, K. (2011). O que cabe no meu mundo. Cedic.

Vasquez, A. S. (2003). Ética Rio de Janeiro:Civilização Brasileira, (24a ed.)

Zabala, A. (1998). A prática educativa: como ensinar. Editora Artes Médicas Sul Ltda.

Zabala; A. (2008). A Prática Educativa: Como ensinar. Artmed; 1998; Reimpressão. 